Ethiopian Journal of Environmental Studies \& Management 8(3): 242 - 251, 2015.

ISSN:1998-0507

doi: http://dx.doi.org/10.4314/ejesm.v8i3.1

Submitted: January 05, 2015

Accepted: March 17, 2015

\title{
UTILIZATION OF PESTICIDAL PLANTS IN PEST MANAGEMENT AMONG SMALLHOLDER VEGETABLE FARMERS IN BAHATI DIVISION, NAKURU, KENYA
}

${ }^{*}$ MUNYUA, C.N. ${ }^{1}$ AND WAGARA, I.N. ${ }^{2}$

${ }^{1}$ Department of Applied Community Development Studies, Egerton University, P.O Box 536, Egerton Kenya

${ }^{2}$ Department of Biological Sciences, Egerton University, Kenya

\begin{abstract}
The use of synthetic pesticides has made impressive impacts on pest control resulting in pest management being synonymous with pesticide use. However, the limitations of synthetic pesticides are evident as pest problems have persisted and also negative effects on human beings and the environment. The study was conducted in Bahati, Nakuru, Kenya to determine the use of alternatives to synthetic pesticides in pest management among vegetable farmers. The results showed that 58 percent of the respondents were men and 42 percent were women. Kales was the most popular vegetable grown by 87 percent of the farmers followed by tomatoes at 79 percent. Aphids, spider mites and caterpillars were the common insect pests. The farmers depended mostly on synthetic pesticides for pest management. The findings indicated that 62 percent of the farmers had knowledge of pesticidal plants which they viewed as a cheap alternative to synthetic pesticides in pest management. However farmers explained that the limitation in using pesticidal plants for pest management was lack of specificity in dosages and methods of application. Pesticidal plants were rated at low to moderate effectiveness. Results indicated need for more research and education on ingredients, methods of preparation and application and target pests. Utilization of pesticidal plants can become a viable pest management option for farmers, after further research and education on preparation and application to improve effectiveness.
\end{abstract}

Key Words: Smallholder farmers, Effectiveness, Pest management, Pesticidal Plants, Vegetable crops, Environmental conservation

\section{Introduction}

Since the first domestication of crops, people have devised ways of managing pests with the aim of increasing yields, improving quality of produce and ensuring profitability in farming. The period following the end of the World War II was especially significant in the use of synthetic pesticides which made impressive impacts on pest control and resulted in pest

*Corresponding Author: Munyua, C.N.

Email: c_munyua@yahoo.com management becoming synonymous with pesticide use (Flint and Gouveia, 2001). However, it was not long before the limitations of reliance on synthetic pesticides became evident as problems of pests persisted and negative side effects on human beings and the environment resulted. Hence, worldwide there is increasing concern on the negative effect of pesticides used in agricultural production. 
For instance, pesticides such as insecticides, herbicides and fungicides directly poison the farmers through contact during mixing and application and indirectly to consumers as residues in harvested produce. Pesticide residues further accumulate in soils, air, and water causing alarm about the health of the environment. The residues in soil not only contaminate surface and underground water due to improper disposal of pesticide containers, but are also picked up by plants and end up in edible portions consumed by human beings (Carson, 1962).

Environmental conservation is currently a central theme in agricultural and rural development projects. Among conservation scholars, there is the belief that an inverse relationship exists between human actions and environmental well-being (Pretty, 1995). In agriculture, the use of pesticides has particularly raised pertinent questions about their effect on human health and the environment. The use of natural products from plants has thus attracted attention of researchers as potential sources of new pesticides. Pesticidal properties of plants have been explored in many parts of the world. For instance tobacco (Nicotiana tabacum) as leaf infusion has been used to kill aphids. Pyrethrum plant from the genus Chrysanthemum found in Kenya gives an insecticidal extract, pyrethrum, which is an active ingredient of many insecticides (Rajapakse and Ratnasekera, 2008). A study on efficacy of plant oils of different plant species against cowpea weevil $C$. maculatas and bean seed weevil C. cinensis revealed that plant oils can completely inhibit oviposition and adult emergence of the weevils. In addition it was observed that only small amounts of the oils were required to attain effectiveness. The oils also showed potential for use in seed dressing (Okwute, 2008). Plants such as Azadirachta indica (Neem) and Tagetes minuta (Mexican marigold) and
Chrysanthemum have also been found to be important pesticidal species (Mwine et al., 2011). In a study of pesticidal plants use in South Uganda, Mwine et al. (2011) note that farmers use parts of plants such as leaves to control various pests. Wood ash was also a common addition to many plant extracts used in pest management. It was however observed that the farmers only gave general names for pests controlled. There was also lack of specificity in formulation and mode of utilization an indication of need for efficacy evaluation of the plant based pesticides.

The potential of plants in pest control can be appreciated in the use of Desmodium (Desmodium uncinatum) and Napier grass (Pennisetum purpurem in management of stem borers (Chilopartelus) and the parasitic weed, Striga spp. in cereal crops. A push-pull technique developed by International Centre for Insect Physiology and Ecology (ICIPE) in Kenya utilizing Desmodium as a push factor and Napier grass as the pull factor has led to a significant control of stem borers. The push-pull technique effectively controls the stem borers in maize (Koechlin, 2000). When Desmodium is planted between maize rows and then three rows of Napier grass are planted around a maize field, the damage caused by the Stem borers is reduced. The scent produced by Desmodium repels the stem borers which are attracted to the Napier grass and consequently trapped by the gummy substance it produces. This results in effective control of the pest and it is noted that only about $10 \%$ of the stem borers survive giving about a $90 \%$ control of the pest. Desmodium has also been found to be effective against Striga or witch weed. In an intercrop of maize and Desmodium, Striga is suppressed by a factor of 40 .

The use of non-chemical alternatives to pesticides has also accompanying challenges. For instance, an evaluation 
study on IPM in smallholder farming systems in Kenya by Loevinsohn et al. (1998) noted that alternatives to synthetic pesticides, especially pesticides from bioactive plant extracts and biopesticides and cultural and physical pest control measures were seen to be problematic. The farmers' main concern was on the time needed to prepare and implement some of the methods. Farmers further questioned the efficacy of physical and botanical control methods. Another observation was that farmers who had undergone training on Integrated Pest Management through Farmer Field Schools in Othaya division in Central Kenya hardly used innovations on botanical pesticides. The farmers' apprehension regarding botanicals in particular was the effective dosages needed which neither they nor their trainers could confidently ascertain. There was a feeling by trainers that researchers should provide information on the correct dosages for botanical pesticides.

Like in any other alternative, pesticidal plants' use implies a methodologically and paradigmatically different plant protection approach closely linked to the attitude of the farmer. A farmer must make concise decisions in terms of the major change needed in pest management a process that requires searching and applying of solutions (Schmidt et al., 1997). Mere awareness of a new idea does not necessarily interpret into adoption of innovations (Rogers, 1995).On receiving a new idea or information from various sources farmers can decide to reject or adopt the innovation. In an Integrated Pest Management study Western Kenya by Chitere (1998) the finding indicated that awareness did not end in adoption indicating existence of other factors. Among the smallholder vegetable farmers Nakuru, no documentation existed on the use of pesticidal plants in pest management hence the purpose of this study.
In Kenya, agriculture is a major occupation for over $70 \%$ of the people living in rural areas with smallholder farmers constituting 81 percent of the farmers in the country (Gautam, 2000). The horticultural sector, in particular, has grown fast as a commercial enterprise for both local and export market for many farmers. Many farmers depend on synthetic pesticides in the production of vegetables despite of the imminent social and economic problems as well as environmental issues that emerge challenging the sustainability of synthetic chemical-based approaches to pest management. A sustainable future in agriculture is more likely if farmers shift to biologically based and diversified approaches that are more stable and of less damage to human health and the environment. The development of pest management interventions that meet the farmers' requirements, however, requires an understanding of the alternative approaches used by farmers in pest management. This is to ensure that farmers use approaches that are meet their needs and at the same time approaches which are environmentally sound. The purpose of the study was to determine pest management practices among smallholder vegetable farmers in Bahati Division, Nakuru.

\section{Objectives of the Study}

The objectives of the study were to:

Describe the general pest management practices used in vegetable crop production by the smallholder vegetable farmers

Identify the kinds of pesticidal plants used in pest management by the smallholder vegetable farmers

\section{Study Area}

The study was conducted in Bahati Division of Nakuru County, Kenya. The location of Bahati is shown on Figure 1. Bahati division covers an area of 650 hectares, with a population of about 158,000 people. The average temperature is 
$20^{\circ} \mathrm{C}$ and average rainfall $1023 \mathrm{~mm}$ per annum. The farm sizes are small with many being less than 5 acres hence the farmers are referred to as smallholder farmers. Bahati is a high potential agricultural area where crops grown are mostly food crops like maize, beans, potatoes, tomatoes and a variety of vegetables. Vegetables in particular are important as a source of income for most of the farmers. Coffee and tea are grown but by very few farmers with large farms.

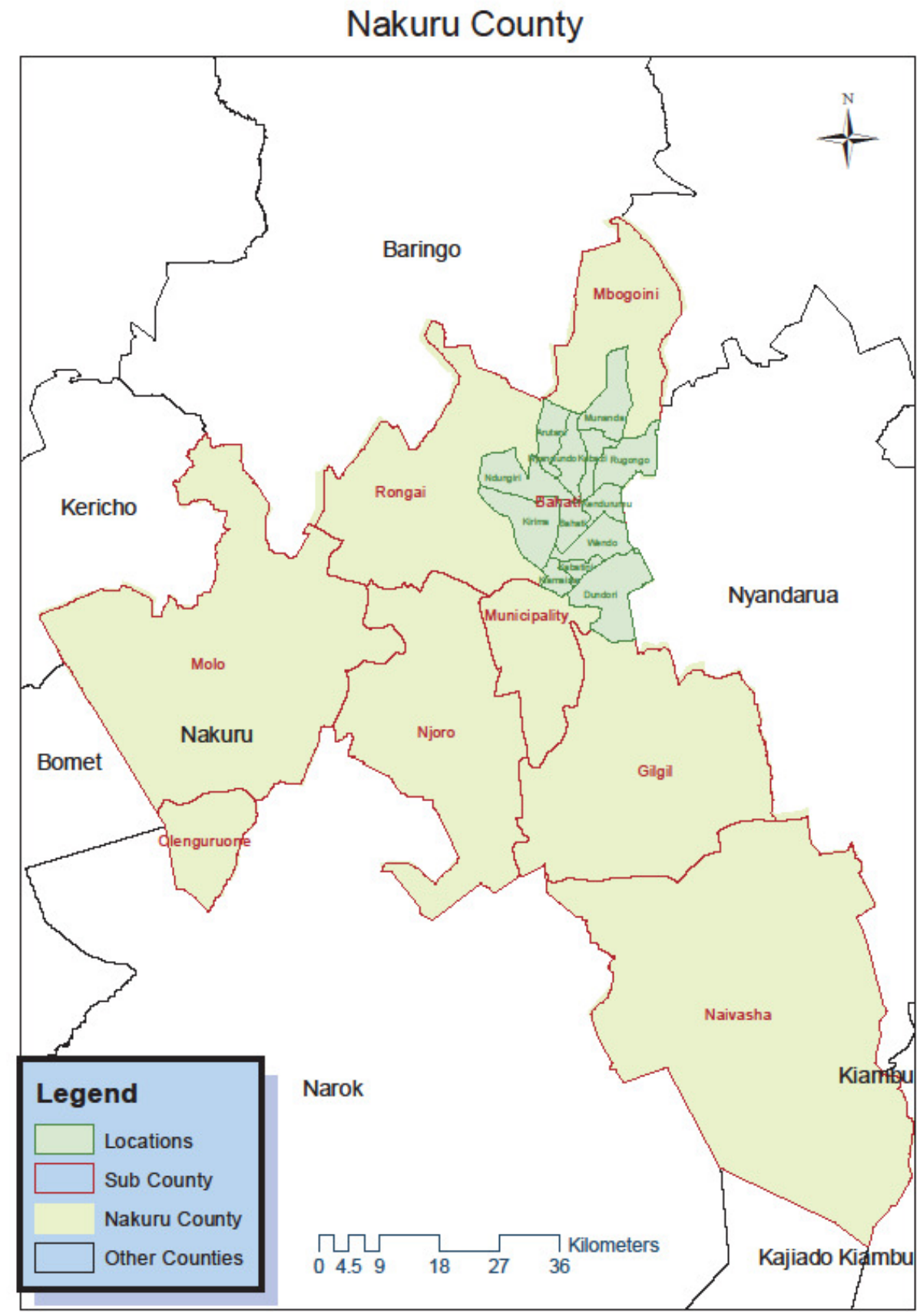

\section{Methodology}

The study design used was a survey. The population of study was smallholder farmers growing vegetables such as tomatoes, kales, potatoes, spinach and cabbages. Smallholder farmers were considered as practicing farmers owning land of less than 2 hectares which is about 
5 acres. The sampling frame of the farmers was obtained with assistance from the Bahati division agriculture office. Purposive sampling was used to select 115 vegetable farmers for the study. The decision to use a purposive sample was because the intention of the study was to reach vegetable farmers who planted vegetables mostly for commercial purpose who could provide the information needed in the study. The farmers included for the study were also required to be growing at least two of the selected vegetables (cabbages, kales, tomatoes, spinach and potatoes) as key enterprises. An interview schedule was used to collect the data. The schedule contained both structured and non-structured questions in order to provide in-depth information on pest management from the farmers. The topics covered in the survey instrument included pest management practices for the different crops, types of chemicals used, dosages and application methods and awareness and use of plant based pest management alternatives by the farmers. Data were collected through face-to-face interviews and analyzed using descriptive and inferential statistics at $\mathrm{p}<0.05$ applying the Statistical Package for Social Sciences (SPSS).

\section{Results}

\section{Demographic Characteristics of the Farmers}

The results showed that approximately 58 percent of the respondents were men and 42 percent were women. About 62 percent of the respondents were in the age range of 21 and 45 years and 38 percent of them between 21 and 35 years. Only 2.5 percent of the respondents were 20 years or younger while about 35 percent were over 45 years old. Approximately 54 percent of the respondents were of primary or elementary level education, while 34 percent had secondary or high school level education. Those who had gone through adult learning or continuing education were about 3percent while a similar percentage indicated having no form of formal education. Vegetable farming was for commercial purposes with most of vegetables being sold as a source of income although some of the vegetables grown were consumed at home. A large percentage of the vegetables produced were sold to local consumers and nearby urban markets. About 77 percent of the respondents indicated they were full time farmers depending wholly on the farm as their source of livelihood and only 22 percent had additional income generating activity. Sixty percent of the respondents owned the farms they cultivated vegetables and about 22 percent were living in an extended family and shared the farms with other family members. The respondents further leased additional land for vegetable growing when the land they owned was not sufficient for their enterprises. The results showed that about 18 percent of the respondents were growing vegetables on leased land.

General Pest Management Practices used in Vegetable Crop Production by the Smallholder Farmers

The study sought to find out the extent of production of different vegetables and the methods of pest control the farmers used to manage pests. Results indicated that the most popular vegetable among the farmers was Kales which was grown by 87 percent of the respondents, followed by Tomatoes at 79 percent. The farmers who planted cabbages, Irish potatoes and spinach were 54, 48 and 46 percent respectively. Few farmers were growing the vegetables on more than 1 acre of land an indication of intensive smallholder farming for the vegetables. The area of the study composed of lowland and upland farming and it was observed that the acreage of tomatoes and cabbages was higher in the 
lowland areas compared to the upland locations.

The major economic pests for all the vegetables were similar. The most commonly cited pests for Kales and Cabbages were insects, such as AphidsCyrthosiphon pisum, Caterpillars- Plutella xylostella (Linnaeus), Spider MitesTetranynchus urticae and cutwormsAgrotis spp. Aphids in particular were considered a major problem of concern for the farmers. All the farmers used different types of synthetic pesticides that were systemic or broad spectrum insecticide to manage these pests. The common insecticides used were KARATE ZEON 50 ec, Danadim or Dimethoate, Ogor 40 ec and Diaznon to control aphids, caterpillars and cutworms. Other pesticides mentioned by the farmers were Bestox PC 50 a pyrethroid, Cyclone $50 \mathrm{ec}$, Polytrin P440 EC,Actara $25 \mathrm{WG}$ and Oshothion $50 \mathrm{ed}$, and Sancozeb $80 \mathrm{WP}$. The farmers indicated that kales and cabbages did not have major problems of disease attacks except for limited encounters of blightPhytophthora infestans and stem rot (Sclerotinia spp.) These were managed using fungicides such as Pencozeb 75 DF, Sulphur, Milraz, and Copper.

In tomatoes a key commercial crop for the farmers, early and late blight were the key diseases. Insect pests of economic importance were spider mites, white flies and fruit borers. The results of the study showed a variation in the choice of pesticides for management of blight in tomatoes. The farmers used fungicides such as Ridomil to prevent blight attack and Milraz as a curative measure where the blight had already affected the Tomatoes.
Milrazin particular was considered as a strong and effective fungicide and thus a regular choice for the farmers. Other pesticides used in tomatoes were Antracol, Danadim and Polytrin P440 EC. The farmers indicated that they chose Polytrin (used for pests in cotton) in tomatoes in the early growth stages to control blight and difficult to manage pests such as spider mites, white flies and fruit borers.

\section{Pesticidal Plants used in Pest Management by Smallholder Vegetable Farmers}

The study sought to find out the awareness and adoption of non-pesticide alternatives to synthetic pesticides among the vegetable farmers. The alternatives were considered to be pest management methods that did not depend on synthetic pesticides and incorporated plant based pesticides. The farmers were asked to indicate whether they used any of the methods that were not based on synthetic pesticides alone or in combination with synthetic pesticides to manage pests on their vegetable farms. The results indicated that about 67 percent of farmers had some information about non-chemical alternatives. The alternatives were mostly plant based in particular plants considered to be weeds. Many farmers used the plant extracts in combination with common household detergents and also wood ash. The farmers' use of the pesticidal plants to manage various pests in different vegetables is shown in Table 1. The farmers also rated the effectiveness of the plants extracts in managing the pests. Most of the combinations of botanical pesticides were rated from low to moderate effectiveness. 
Table 1: Pesticidal Plants used in management of pests/diseases on various vegetables and ratings on effectiveness

\begin{tabular}{|c|c|c|c|}
\hline $\begin{array}{l}\text { Pesticidal Plants and Other } \\
\text { Combinations }\end{array}$ & $\begin{array}{lcc}\text { Insect } & \text { Pests } & \text { or } \\
\text { Disease Managed } & \end{array}$ & Vegetable & Rating on Effectiveness \\
\hline $\begin{array}{l}\text { Stinging Nettle (urticadioca) }+ \\
\text { Detergent powder (Omo) }\end{array}$ & $\begin{array}{l}\text { Blight (Late and } \\
\text { Early blight) }\end{array}$ & Tomatoes & $\begin{array}{l}\text { Effective only when its } \\
\text { not very cold }\end{array}$ \\
\hline $\begin{array}{l}\text { Mexican Marigold (Tagetes } \\
\text { minuta) }\end{array}$ & Spider Mites & Tomatoes & Fairly effective \\
\hline \multirow{3}{*}{ Mexican Marigold + Wood ash } & Caterpillars & Kales & Moderately effectiveness \\
\hline & $\begin{array}{l}\text { Caterpillars } \\
\text { Aphids }\end{array}$ & $\begin{array}{l}\text { Kales } \\
\text { Cabbages }\end{array}$ & $\begin{array}{l}\text { Low effectiveness on } \\
\text { caterpillars but moderate } \\
\text { on aphids }\end{array}$ \\
\hline & $\begin{array}{l}\text { Bollworms and white } \\
\text { flies }\end{array}$ & Tomatoes & Moderate effectiveness \\
\hline $\begin{array}{l}\text { Mexican Marigold }+ \text { Chillies } \\
\text { (Capsicum anпиum) }\end{array}$ & All diseases and pests & Tomatoes; Kales & Moderate effectiveness \\
\hline $\begin{array}{l}\text { Mexican Marigold+ Chillies+ } \\
\text { stinging nettle + soap }\end{array}$ & Blight & Tomatoes & Very effective \\
\hline $\begin{array}{l}\text { Mexican Marigold + Pyrethrum } \\
\text { Chrysanthemum spp. }\end{array}$ & All pests & Tomatoes & Low effectiveness \\
\hline Tobacco (Nicotiana tabaccum) & $\begin{array}{l}\text { White Flies } \\
\text { Caterpillars }\end{array}$ & Tomatoes & Moderate effectiveness \\
\hline $\begin{array}{l}\text { Mexican Marigold + Aloe Vera } \\
\text { (Aloe sp)+ Cow's urine }\end{array}$ & All pests & Kales, Spinach & Moderate Effectiveness \\
\hline \multirow[t]{2}{*}{ Chillies pepper } & Aphids & Kales & Moderate effectiveness \\
\hline & Spider mites & $\begin{array}{l}\text { Tomatoes, } \\
\text { Cabbages, Kales }\end{array}$ & Very Effective \\
\hline Mexican marigold+ Tobacco & Aphids, white flies & Tomatoes & Very effective \\
\hline Mexican marigold + Tobacco & Cutworms & Kales & Low effectiveness \\
\hline $\begin{array}{l}\text { Stinging Nettle }+ \text { Black Jack } \\
(\text { Bidens pilosa })+\text { Mexican } \\
\text { marigold }\end{array}$ & Aphids & All vegetables & Low effectiveness \\
\hline 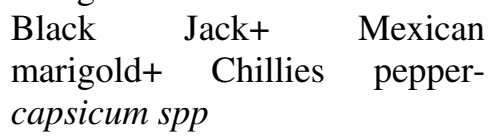 & Caterpillars & Tomatoes & Low effectiveness \\
\hline $\begin{array}{l}\text { Stinging Nettle + 'Maigoya' } \\
\text { Plectranthus barbatus+Chillies }\end{array}$ & Caterpillars & All vegetables & Moderate effectiveness \\
\hline $\begin{array}{l}\text { Mexican Marigold+ Mathakwa } \\
\text { Vernonia auriculifera }+ \text { Chillies }\end{array}$ & Caterpillars & Tomatoes & Very effective \\
\hline $\begin{array}{l}\text { Datura } \\
\text { apple) }\end{array}$ & Aphids & Cabbages & Moderate Effectiveness \\
\hline $\begin{array}{l}\text { Sodom Apple (Calotropis } \\
\text { procera }\end{array}$ & Aphids & Kales & Moderate Effectiveness \\
\hline Onion & White flies & Cabbages & Moderate effectiveness \\
\hline Tobacco & Caterpillars & Kales & Moderate effectiveness \\
\hline Chillies Pepper + Wood Ash & Cutworms & Cabbages, Kales & Very Effective \\
\hline $\begin{array}{l}\text { Pyrethrum + Chillies + Mexican } \\
\text { Marigold }\end{array}$ & Aphids & Tomatoes, Kales & Very Effective \\
\hline
\end{tabular}

Perception of Farmers about Potential of Plant-Based methods of Pest Management

The farmers were asked to indicate their opinion about the plant based methods of pest management. Although the farmers knew about the pesticidal plants use and some had tried to use them on their vegetables, opinions varied about their 
effectiveness and usefulness in vegetable production. The farmers explained that the alternative methods can help to overcome the harmful effects of synthetic pesticides. The farmers further acknowledged that less dependence on synthetic pesticides was safe for their health and the environment. The pesticidal plants can also provide a cheap alternative of pest management since the materials used such as the weeds and herbs were locally available on their farms. In spite of the positive views of the farmers towards botanical alternatives to synthetic chemicals, there was a general agreement that they would only use them if their effectiveness can be well proven. The farmers thus indicated that they could not adopt the pesticidal plants on a large scale in managing pests on their vegetable crops. The farmers indicated that although sometimes the pesticidal plants provided protection for their crops, determining the correct dosage, methods of application and spraying interval posed a problem making farmers unsure of their effectiveness. Among the few farmers who indicated that they had tried some of the plant based alternatives, their verdict was that, even after frequent trials they had not observed any positive sustainable outcome in terms of effective pest control.

Some of the observations by farmers on use of the pesticidal plants in pest management were: when wood ash was used to control ants, it prevented the growing of other plants and caused rotting and scotching; the alternatives were slow in giving results posing a risk of crop failure if they did not control the target pests on time; the use of plant based pesticides involved too much time to collect and prepare hence their use was cumbersome and time consuming. The lack of information on rates of application could also lead to side effects on the consumers and the farmers. The farmers indicated that vegetables cannot be grown productively without the use of synthetic pesticides. There was also the view that, the alternative pesticidal plants methods can be used only for prevention purposes since they lacked the potency of synthetic pesticides.

\section{Discussion}

The results showed that there were more men compared to women growing vegetables. The differences in the number of men and women engaged in vegetable farming may be due to the commercial nature of the enterprise which would attract more men than women. It is a common phenomenon that when agriculture changes from subsistence to commercial enterprise with increased money returns the disadvantaged groups are overcome by those with more say and power (Tesfa, 2000). In Bahati, the culture of the inhabiting community is that land belongs to men. Women use the land courtesy of men and when more gains arise from the agricultural activities, men tend to renew their interest in farming. The age range of many of the farmers was 21-45 years and indication that the respondents were relatively young. The economic nature of the vegetable enterprise could explain the attraction of young people most of whom have no other gainful form of employment. The results indicate that about half of the respondents had elementary education and secondary education. Most of the respondents, therefore, had some form of education that equipped them with the ability to understand the basics of farming, use of pesticides and any other alternative techniques of pest management.

Vegetables were grown in the lowlands and uplands. The lowland areas of Bahati are characterised by a high water table and higher rainfall which made it possible for the farmers to grow vegetables especially cabbages through irrigation. Cabbages like many vegetables are best grown under irrigation and the high water needs for 
cabbages were met in the lowland areas.In the upland areas, the farmers relied on rainfall for vegetable growing and Kales were a preferable vegetable because the crop would thrive even without irrigation. Kales and Tomatoes were viewed to fetch better prices in the market explaining their popularity among the farmers.

It was observed that most of the farmers gave only the general trade names of the pesticides and did not have in-depth knowledge of the chemical composition. These findings agree with Mwine et.al (2011) results of their study in South Uganda where they indicate that the farmers tend to give general names of pests controlled indicating little knowledge of science of the pests. Similarly, the farmers in Bahati could interchange insecticides with fungicides with little scientific base for choice and ignorance of possible harmful side effects of such actions. This could explain the fact that farmers' choice of pesticides was based on opinion about the outcome upon application. For instance, the farmers perception of an effective insecticide is that which "kills all the insects" totally eliminating them in the field. Popularity of Polytrin was based on this premise as a strong pesticide for blight and mites used soon after planting but stopped during flowering and fruiting stages of the tomatoes. The results thus showed great dependency on pesticides among the vegetable farmers in Bahati division.

However, the farmers appreciated the need for alternatives to synthetic based pesticides whose negative side effects the farmers were aware. The vegetable farmers had information about pesticidal plants and many explored their use in managing pests. The plant extracts were also combined with others or added detergents or wood ash implying that the farmers considered them ineffective when used alone. Although the findings indicated that the farmers in Bahati were aware of plant based alternatives to synthetic pesticides. But as pointed out by Rogers (1995), awareness of an innovation does not necessarily interpret into adoption. The innovation has to undergo a process of analysis where farmers seek for more information, test the idea and finally decide whether to accept or reject it. The farmers' suggestion was that more research and education of the farmers was needed. More information, education and thorough training would be needed for the farmers to move from the awareness stage and try the practices on their crops. The kind of learning that farmers must be taken through are specific ingredients, dosages, methods of preparation and application and specific pests and vegetables to target. These views by the farmers agree with findings by Schmidt et al. (1997) and Loevinsohn et al. (1998) of problems of preparation, effectiveness, dosage and attitude towards new ideas with respect to use of pesticidal plants for pest control.

\section{Conclusions}

The farmers acknowledged the potential of pesticidal plants in pest management when considering their availability, less cost and less harm to human beings and the environment. The farmers major concern was the efficacy of the plant based pesticides because even the ratings on effectiveness given were somewhat general and this made the farmers to prefer the use of synthetic pesticides due their fast action. The active ingredients or the chemical nature of the various plant extracts were unknown hence the farmers were not certain on the precautions to take during their preparation and application. The challenge in the use of the plant based alternatives was therefore the uncertainty in methods of preparation and application, quantities or dosages required and frequency of application and possible toxicity from their use. These concerns 
about the use of pesticidal plants have also been raised by other researchers especially the aspect of efficacy and dosages.

\section{References}

Carson, R. (1962). Silent Spring. New York: Houghton Mifflin Company.

Chitere. O.P. (1998). Diffusion and adoption of farm technologies among resource-limited farmers: experiences from ICIPE/UNECA Integrated Pest Management Project in Western Kenya, 44(2): 49-52.

Flint, M.L. and Gouveia, P. (2001). IPM in Practice: Principles and Methods of Integrated Pest Management. Oakland, CA: University of North California.

Gautam, M. (2000). Agricultural extension: The extension experience. Washington D.C.: The World Bank

Koechlin, F. (2000). Natural success stories- the ICIPE Kenya

Loevinsohn, M., Meijerink, G. and Salasya, B. (1998). Integrated Pest Management in Smallholder farming systems in Kenya: Evaluation of a pilot project. Kenya Agricultural Research Institute.

Mwine, J., van Damme, P., Kamoga,Kudamba, M.N. and Jumba, F. (2011). Ethnobotanical Survey of Pesticidal plants used in S. Uganda:
Case Study of Masaka district. Journal of Medicinal Plants 5(7): 1155-1163.

Okwute, S.K. (2008). Plants as Potential Sources of Pesticidal Agents: A Review. In R.P. Soundararajan. Pesticides - Advances in Chemical and Botanical Pesticides.

Pretty, J. (1995). Regenerating agriculture: Policies and practice for sustainability and self-reliance. London: Earthscan Publications Ltd.

Rajapakse, R.H.S. and Ratnasekera, D. (2008). Pesticide potential of some selected tropical plant extracts against Callobruchus maculatas (F) and Collobruchus (L). [Tropical Agricultural Research and Extension, 11, 2008]

Rogers, E.M. (1995). Diffusion of innovations ( $4^{\text {th }}$ Ed.) New York: The Free Press.

Schmidt, P., Stiefel, J. and Hürlimann, M. (1997). Extension of complex issues: Success factors in

Integrated Pest Management. Gallen, Switzerland: Swiss Centre for Development Cooperation.

Gebremedhin, T.G. (2000). Problems and Prospects of the world Food Situation. Journal of Agribusiness, 18(2):221-236. 